\title{
SITE-SPECIFIC PIVOT SPRINKLER ASSESSED FOR SAVING WATER IN AGRICULTURE
}

\section{H. Mostafa ${ }^{1}$ and H-H Thormann ${ }^{2}$}

\section{ABSTRACT}

All center pivot systems currently available from the manufacturers can apply different rates of water during irrigation by varying speed. However, these systems generally cannot change the application rate along the length of the pivot boom. The whole system can speed up to apply less water or slow down to apply more. If a pivot is simultaneously crossing areas that are wet (drainage area) and dry (sandy), then a traditional system would have to address one problem of over- or underirrigate one area or another. Conversely, a variable-rate pivot could apply less water to the wet area and more to the dry area at the same time. The system at the current study is a true variable rate center pivot. The system was developed and tested for two years where the water saving and sugar beet production were measured. Due to the dry weather in most of a season, the differences were clearer than the high rainy year during another season. The results indicated water saving in the second season $(102 \mathrm{~mm})$ while low change existed in water use in the first season $(36 \mathrm{~mm})$. Sugar beet and sugar production were similar under full irrigation (100\% of water balance) and VRI (80\% of water balance) for loamy soil (medium quality) for both two seasons, which means that we can obtain the same production with water saving.

Keywords: Variable rate irrigation, water saving, sugar beet, site-specific pivot.

\section{INTRODUCTION}

Tmproving the level of agricultural data acquisition and detection continues to be a topic of concern because automation of agricultural production is an important factor limiting grain production worldwide. e.g., achieving higher yield per unit of water is one of the most important challenges in water-limited agriculture.

\footnotetext{
${ }^{1}$ Agric. Eng. Dept., Faculty of Agriculture, Benha University, Egypt; harby.mostafa@fagr.bu.edu.eg

${ }^{1}$ Federal Research Institute for Rural Areas, Forestry and Fisheries, Institute of Agricultural Technology, Braunschweig, Germany
} 
The use of precision agriculture techniques gives agronomists the potential to apply new and continuously developing technologies which help to manage the production (Konstantinos et al., 2007). Some of these technologies are GPS, GIS, Remote Sensing, variable Rate Technology, Machine Controls, Smart Sensor Arrays and WSN technology (Kikiras et al., 2003; Vellidis 2005; Liu and Li, 2013).

The potential to save water at the farm scale depends on the capabilities of the irrigation system and the commitment of the operator to implement water-saving practices and technologies. Adoption of site-specific technologies could potentially extend these water savings even more. Site-specific irrigation could also play a major role in maximizing net returns when implementing limited or deficit irrigation strategies in water short areas and in the optimal use of precipitation in humid regions (Evans et al., 2013).

The development of mobile sprinkler systems has provided more than convenient irrigation methods. Of all the irrigation systems, these machines offer the greatest potential for uniform applications as well as being readily adaptable for adaptive control of spatially varied applications. Significant progress has been made in hardware development for the control of center pivots and lateral moves to deliver a precision irrigation system, with much of this work conducted in USA. Recent research in Australia (McCarthy et al., 2010) has addressed the need to develop appropriate decision making tools to significantly extend the potential of center pivots and lateral moves to provide optimal precision irrigation.

Center pivots have recently been integrated with variable rate irrigation (VRI) technology, providing a tool to improve water application for irrigation. Most VRI technology has been limited to speed control of a pivot to increase or reduce application depth along the entire pivot lateral.

More recent technology has implemented either sprinkler flow rate controls or solenoids to limit application depths over certain specified collections of sprinklers or zones along the pivot. Varying the flow rate or time the sprinkler operates over a specified area, adjusts the pivot application depth. This VRI technology has been shown to reduce the 
total water application depth that is distributed over the specified area when matched to detailed soil information (Hedley and Yule, 2009).

With VRI, understanding where the technology is efficient and likewise inefficient is critical to understanding the limitations and ideal conditions for which it may be used. To apply a uniform depth within the sprinkler zone or over a management zone within the field is critical (Evans et al., 2012). These technologies promise the possibility of elevating agricultural irrigation techniques to the next level, with the hope of optimizing profit, and increase the efficiency of water use in crop production in the Ontario potato sector. The outcome of VRI is the use of less water through optimizing water application, thereby increasing efficiency of crop production and reducing risk of drainage and nitrate leaching. Earlier research has shown that variable-rate irrigation saves between 9 and $26 \%$ of irrigation water, with accompanying energy savings, as well as reducing runoff and drainage by up to $55 \%$, which reduces the risk of nitrate leaching (Fraser, 2011). Further, the larger economic benefit is the increased certainty of having sufficient water to grow high value crops or to irrigate larger areas with the same water resource. Hedley et al. (2009) evaluated the benefits of using variable rate irrigation for selected crops (dairy pasture, potatoes, maize grain). They reached water saving of $9 \%$ (dairy pasture), $13 \%$ (potatoes) and $19 \%$ (maize grain).

This work represents a new innovative approach to sugar beet crop irrigation through the application of VRI. Through showcasing a demonstration site of VRI technologies via various knowledge technology transfer opportunities, it is envisioned that the benefits of VRI will be potentially incorporated by other producers for enhanced on-field water management/ application and environmental sustainability for other high value. Specific objectives of the project include:

1. Developing and field testing an adaptable, reliable and user friendly variable rate center pivot irrigation system,

2. Evaluating the impact of variable rate irrigation on crop production and water-saving. 


\section{MATERIALS AND METHODS}

The method is referred to site-specific irrigation as Variable-Rate Irrigation (VRI). This system easily retrofits onto existing center pivot irrigation systems. The process for using the VRI system is as follows:

1. Pivot information is entered into the desktop software;

2. Desired application rates are defined in the desktop software;

3. A control map is transferred from desktop PC to the controller via data card;

4. The controller determines pivot angle via GPS;

5. Based on the control map, the controller optimizes pivot speed and/or cycles sprinklers (and/or end gun) to set application rate.

This research was conducted at Niendorf II, Uelzen, Germany as a subproject of European Union project (EU-AQUARUS) from 2011 through 2014. The site-specific irrigation control system was designed to implement research evaluating irrigation method efficiency under irrigated crop rotation of sugar beet (Beta vulgaris L.).

Establishing a strategy of site-specific irrigation, developing of an application map and determining management zones are initially important.

The application map comprises the farm soil map, measuring electrical conductivity and soil sampling for determining water storage capacity of the soil.

The technical implementation on the trial field was carried out with an existing center pivot irrigation machine. For the center pivot, a special nozzle control with solenoid valves was developed and installed.

\section{Measurement of variability in the soil}

Initial information is contained in a farm soil map. In the next step the electrical conductivity was measured with an EM38 device (Figure 1).

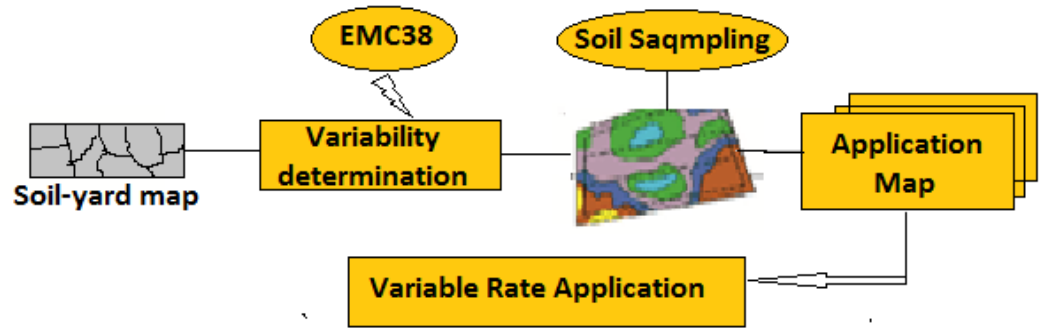

Figure (1): Strategy of an application map for site-specific irrigation. 
For these measurements, the field was traversed every 5 meters and each measured EC value was assigned a GPS value. The measuring depth was up to $150 \mathrm{~cm}$. A map showing soil differences as a function of conductivity was generated (Figure 2).

Due to different EC values of the soil, the map was divided into three management zones (yellow "sandy", green "sandy loam" and red "loamy"). In addition, at these management zones 24 monitoring points were set and at each point soil samples were taken for determination of field capacity and wilting point.

For the experiments only one semicircle was used (the left side in Figure 2). For a more precise determination of the soil type, a soil structure assessment has been performed and because of the low differences in soils, the management zones for sprinkling were reduced to two (yellow "sandy" and red "loamy"). These values formed the basis for the application map which was needed for the site-specific distribution of water with the center pivot.

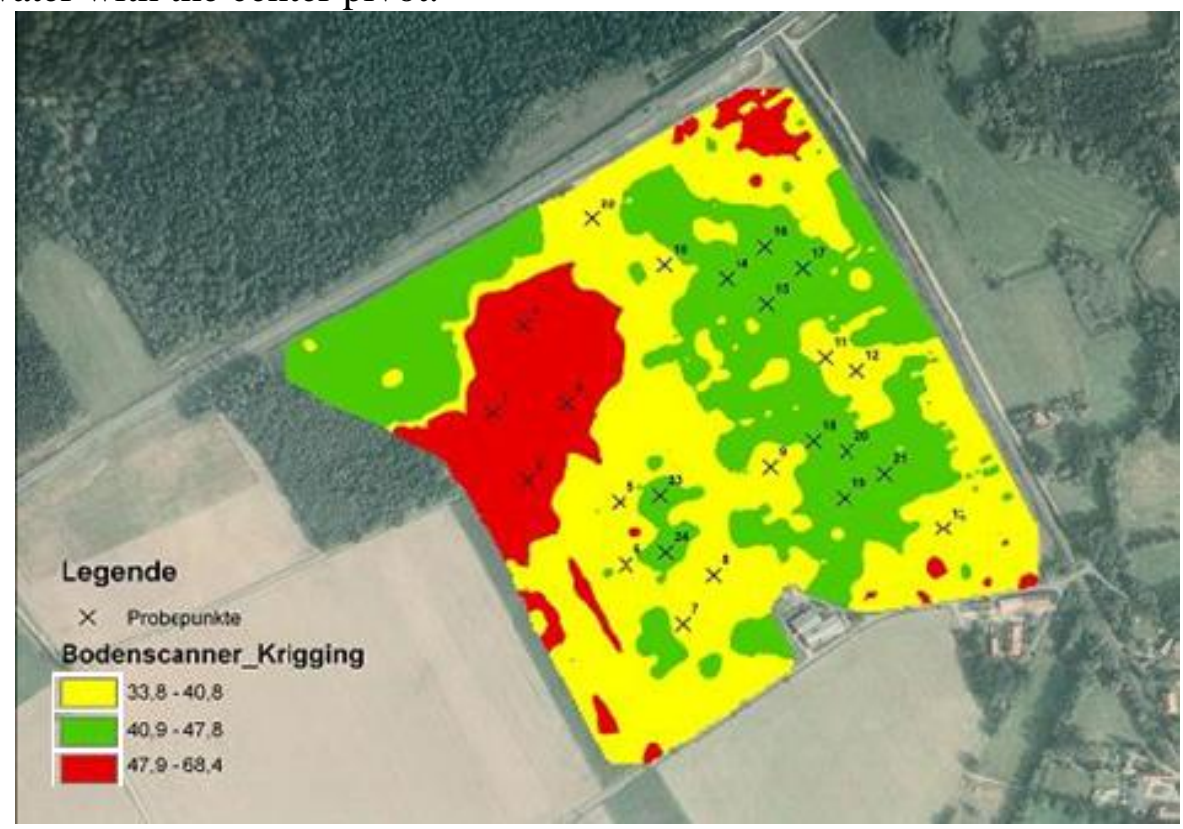

Figure (2): Conductivity map in millisiemens $(\mathrm{mS})$ of the experimental field with the different management zones.

\section{Irrigation technology}

For the implementation a site-specific irrigation center pivots and moving laterals irrigation machines are very well suited. Basic experiments were 
carried out on the fields of the Thünen Institute (TI) in Braunschweig, Germany (Al-Kufaishi et al., 2005; Hezarjaribi et al., 2008) and the results were implemented in the project in a farm in Niendorf II (Thörmann et al., 2012).

The center pivot used in Niendorf II is property of a farmer. It has a sprinkling radius of $295 \mathrm{~m}$ and is equipped with an end gun at the end of the overhang, which is activated automatically in the corners by a solenoid valve and a sector setting. In total, 27 ha can be irrigated with the center pivot.

For water distribution, the center pivot was equipped with rotating plate nozzles (Nelson R3000) mounted at a spacing of $6 \mathrm{~m}$. To keep the volumetric flow rate of the nozzle constant over the entire width of the machine, pressure reducing valves (Nelson High Flow 1.38 bar) were placed in front of the individual nozzles. In addition, solenoid valves were installed in front of the nozzles to control the management zones.

\section{Technical implementation of the control for the different irrigation rates}

Site-specific irrigation means an adaptation of the irrigation rates to the specific requirements of the different management zones. The water flow to the individual nozzles of center pivots or moving laterals must be regulated by valves in the supply lines. The control of the valves was carried out automatically based on the application cards, which were entered into the control system. Figure 3 shows the interaction of the control components. The whole system including the solenoid valves operates at $24 \mathrm{~V}$ direct current obtained via a three-phase power supply from the $380 \mathrm{~V}$ supply of the machine drive. The main part of the system is the controller. Through its display and keyboard all settings of the system can be made.

Since the controller itself could only control 5 solenoid valves and the end gun, it was possible to expand the system as required via sub-divider by up to $6 \times 8$ valves. The sub-dividers were connected and managed via a simple 3-wire (RS485) to the controller.

Within the project, the preference was given to the direct control of the nozzle by electric solenoid valves. These valves have a power requirement of $18 \mathrm{~W}$ atts and close safely even at an operating pressure of 
up to 10 bar. During this project, no failures or malfunctions of the valves have been so far observed.

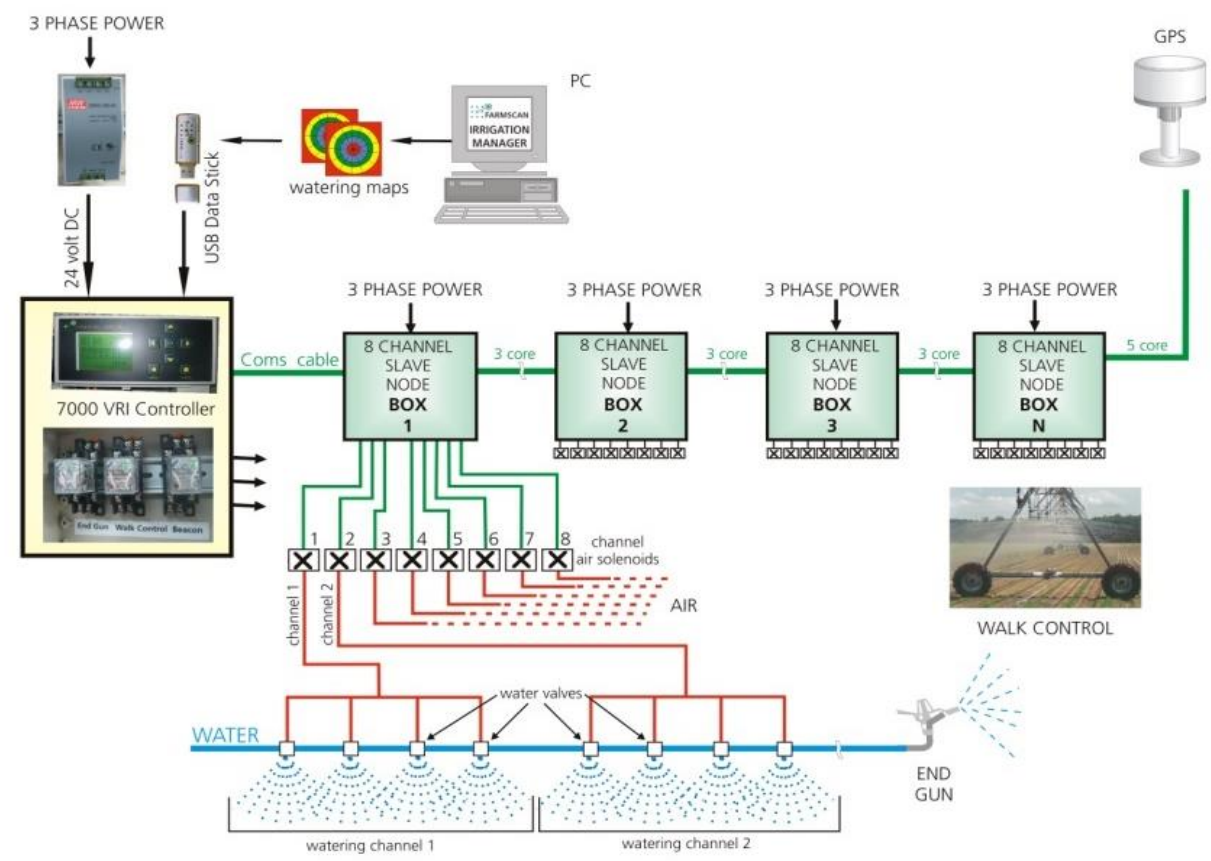

Figure 3: Operation of the control VRI 7000 (Farmscan, 2011).

The application data for programming the controller are generated at the computer with the software "Irrigation Manager", provided by Farmscan, using a graphical interface (Figure 4) and entered into the controller using a USB stick.

Up to 5 different irrigation variants with 11 different irrigation levels can be simultaneously stored and selected as required via a menu on the controller. To determine the irrigation rates for the irrigation area which can be divided into a maximum of 360 sectors of $1^{\circ}$, the dimensions of the machine, such as the coordinates of the tower, number and position of the nozzles, the length of the boom and the position of the GPS receiver on the boom can be entered. The GPS receiver, as shown in Figure 3, is attached as far away from the central tower of the center pivot as possible because the inaccuracies in the determination of position have the slightest effect on the calculation of the angular position of the boom. In the project, a DGPS receiver with satellite-based correction signals (EGNOS) is used whose accuracy has proven to be sufficient for the control. 


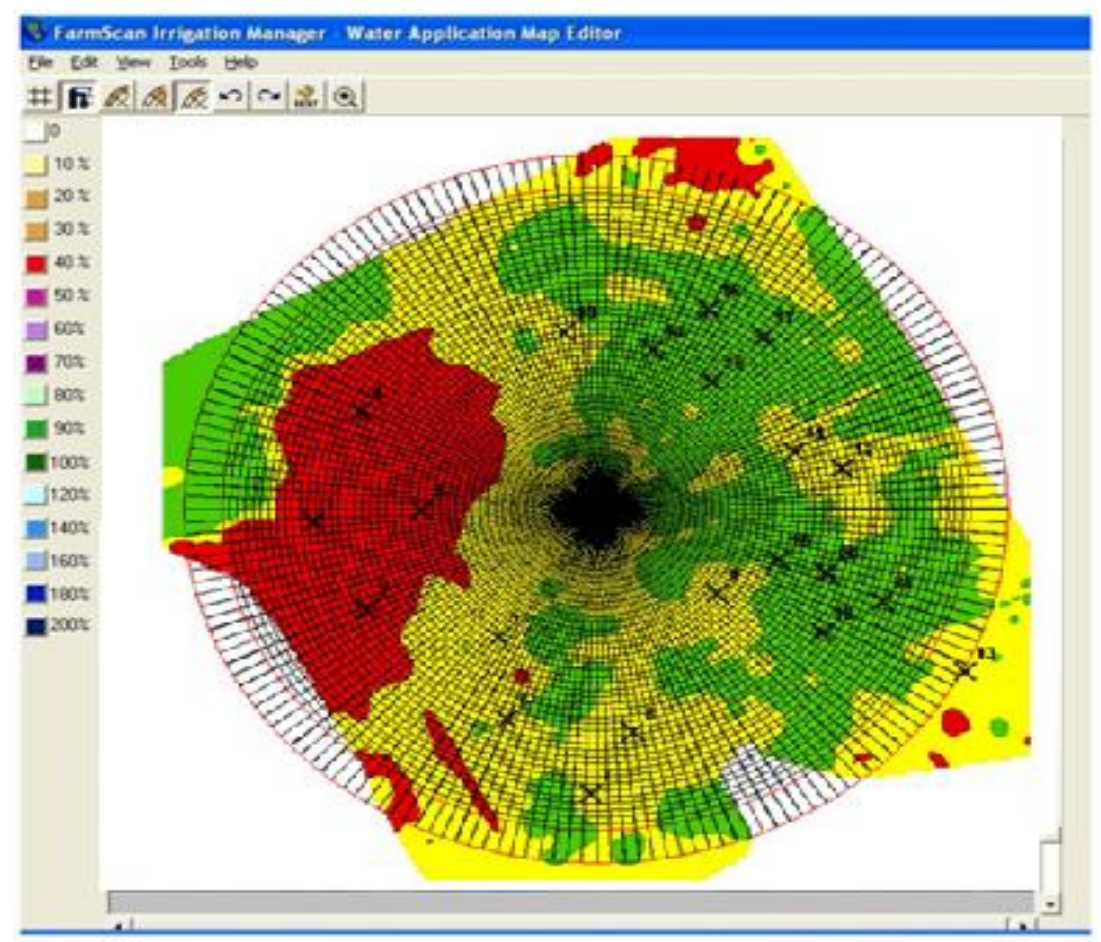

Figure (4): The Farmscan Irrigation Manager ${ }^{\mathrm{TM}}$ software provides for development of application maps.

The installation of the control components on the center pivot was unproblematic. The sub-divider for controlling the solenoid valves were installed in watertight switch boxes on the boom within the range of the driving towers, so that no additional ladders for maintenance were needed. Moreover, the power supply line from the distribution box of the irrigation machine could be shortened. After initially marginal problems which could be solved by updating the operating software by a USB stick, the control system has been working correctly.

The required irrigation rate was adjusted with the existing percentage timer on the central tower. The different predetermined amounts of water for the management zones, which are entered in the controller, were applied without any more setting.

To determine the actual soil moisture in the management zones, four monitoring points measuring stations were installed. A measuring station consists of two EasyAG soil moisture probes and a compact data transmission device. The EasyAG probes (Sentec Company) are about 60 
$\mathrm{cm}$ long and have a measuring range of $0-50 \mathrm{~cm}$ depth. The sensors measure the soil moisture by the electrical capacity. Thereby, a high frequency electric field is generated around each sensor. In this field, the soil moisture is measured and transmitted for the various soil depths by remote data transmission to the farmer's office. The transferred data are processed and provided to the user for the purpose of irrigation control as single values in relative volume $\%$ or as the sum of values over the entire probe in daily AWC (available water capacity).

In addition to the soil moisture data, the current rainfall, soil- and air temperature, the position of the center pivot irrigation and some other technical parameters are transferred daily.

\section{Irrigation strategy}

The experimental site was irrigated according to the strategy of sitespecific irrigation. That means the center pivot was driven to the management zone, which first reaches soil moisture of $50 \%$ of AWC, and then this section was watered up to soil moisture of $80 \%$ of AWC.

To monitor the daily time of use, the climatic balance irrigation was established with the irrigation controller model AMBER by the German Meteorological Service (DWD). The five-day prediction of water demand was created daily and allowed the further specific irrigation.

AMBER is counseling software developed by the DWD for calculating soil moisture and irrigation control. The program is based on the climatic water balance and is interlinked with agro-meteorological, soil physical, phytopathological and other agricultural and forestry contents.

The data of the agricultural meteorological weather station of the DWD, together with the values determined on the trial field by the four sensor stations in the field, offer a high comfort for an exact calculation of the irrigation needs at the individual trial plots.

Sufficient irrigation was applied to keep the root zone soil water profile between critical water content and field capacity. Irrigations were sequenced as needed to meet this condition for all treatments.

Since the water holding capacities of the management soil zones are different, the required amount of water was reduced to $80 \%$ on the 
targeted area with the higher water holding capacity (loamy). A water reduction of $20 \%$ compared to the plot with $100 \%$ water balance (sandy) is thus given (Figure 2). Factors for starting and controlling the irrigation system serve the AWC of the soil which is controlled by AMBER. The irrigation starts on all areas when $50 \%$ of the AWC is reached.

Two control plots were created in the loamy area, one was irrigated with $100 \%$ for comparing with $80 \%$ under VRI and the other one didn't irrigate (only rains) verify the benefits of irrigation even in humid or subhumid areas.

To verify the variable-rate functionality and that the pivot's sprinkler uniformity was not adversely impacted by the addition of VRI controls, a series of application tests were performed on the pivot. The first test involved operating the pivot with VRI engaged but all sprinklers at $100 \%$ cycle time for $100 \%$ application rate. In effect, this test produced a baseline uniformity of the pivot. The second test instructed the VRI control system to operate all sprinklers to produce $70 \%$ application rate. The third test consisted of setting various target application rates along the pivot.

In the pivot experiments, two rows of collectors beginning $15 \mathrm{~m}$ from the pivot's center point were located at $4 \mathrm{~m}$ spacing along the pivot radius and $0.4 \mathrm{~m}$ height used to determine applied water depth. Collectors were cylindrical in shape and graduated in millimeter (rain gauges). The pivot was operated at $15 \%$ speed timer setting. During the uniformity testing, speed control was not engaged to keep the pivot travel speed constant. This test is similar to the ASABE Standard S436.1 (ASABE, 2012) for testing uniformity of center pivot irrigation systems.

\section{RESULTS AND DISCUSSION}

\section{Variable-rate functionality and pivot's sprinkler uniformity}

The results of the $100 \%$ and $70 \%$ application rate tests are shown in Figure 5. The $100 \%$ data provided a "normal" or baseline application amount to which other application rates could be compared. The amount of irrigation water collected in each cup was used to determine 
coefficients of uniformity (CU) by the Christiansen Method. For the $100 \%$ test, the CU was $92.9 \%$. The $70 \%$ test produced a CU of $91.1 \%$. These CU's indicate a uniform application for both rates.

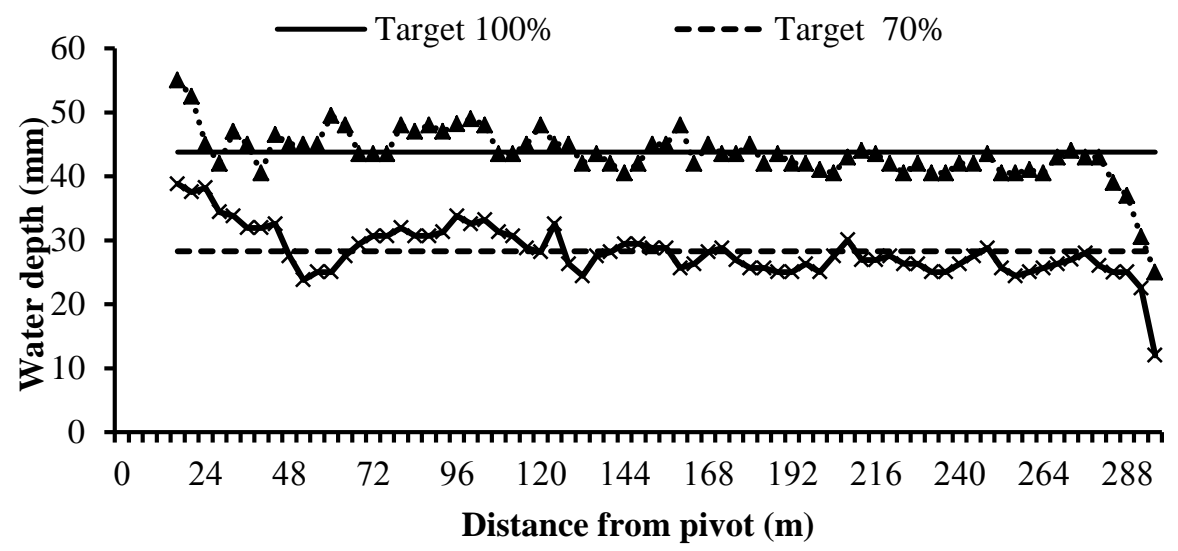

Figure (5): Water destribution a long the pivot for $100 \%$ and $70 \%$ tests

The mean application for the $100 \%$ test was $43.8 \mathrm{~mm}$ with standard deviation (SD) of 4.8 and a coefficient of variation (CV) of 0.093 . The $43.8 \mathrm{~mm}$ value became the baseline for further comparisons. The mean application for the $70 \%$ test was $28.3 \mathrm{~mm}$ with SD of 5.1 and CV of 0.148 . This mean differed from the expected mean (30.6) by $3.8 \%$. This could be attributed to application losses that often occur in center pivot irrigation systems and which have a greater effect at lower irrigation rates.

The results of the variable rate testing are shown in Figure 6. The pivot's lateral was divided randomly into 6 sub-sections $(0,100,50,70,100$ and $70 \%$ of baseline rate as various target application rates) and the testes were done. All of sub-section 1 and most of sub-section 2 were located within the first span of the pivot. The uniformity of application from sprinklers in this span is usually low (CU 84.1\%). The CU values for sections 3, 4, 5 and 6 were each quite uniform $(92.1 \%, 95 \%, 95 \%$ and $89.2 \%)$. The variable-rate scenario for the VRI system was able to achieve target application amounts fairly well. However, these tests measured variations in application only along the pivot mainline. 


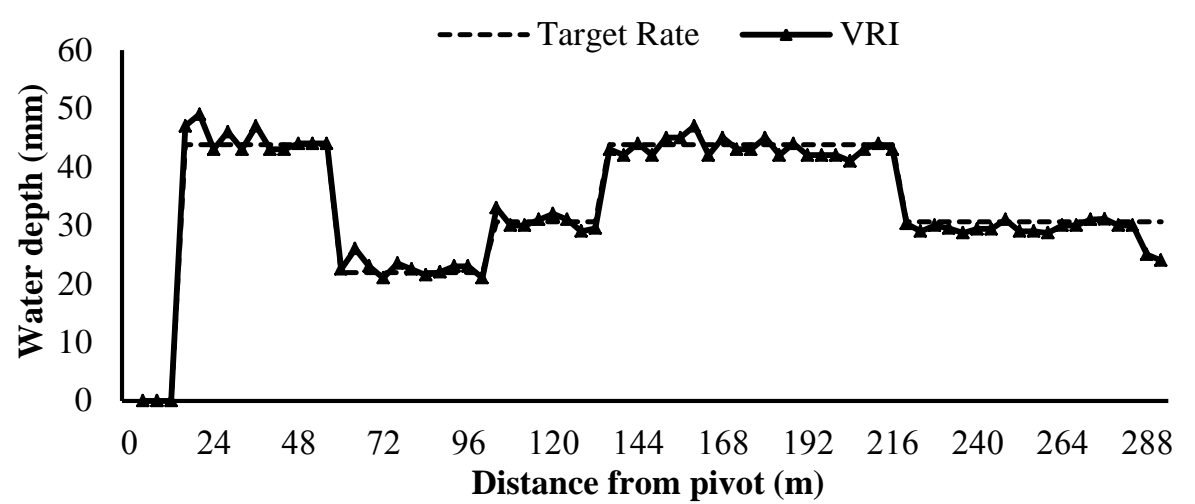

Figure (6): Water destribution along the pivot for variable rate tests.

\section{Water saving and crop yield}

Visual observations and use of a soil probe indicated the soil moisture was adequate in the area receiving $80 \%$ of the base application depth.

In 2013 sugar beets were grown on the trial plots. In the year 2013, there were several heavy rain events in May, June and July. This high rainfall reduced the number of irrigations. In the growing season, about $433 \mathrm{~mm}$ of precipitation fell on the experimental site. The first irrigation was on 19 July. Also, 4 irrigation rates followed up to September with a total of 5 irrigation applications with up to $206 \mathrm{~mm}$ for $100 \%$ water balance (low soil quality) and $170 \mathrm{~mm}$ for $80 \%$ water balance (medium soil quality).

Seven plots were created with $10 \mathrm{~m}^{2}$, each with four replicates. At the end of each growing season, the 28 field plots were harvested. Extensive analyzes were performed in Uelzen sugar factory for measuring the sugar production. The main results with the corresponding irrigation levels in the plots are shown in Table 1.

In 2014, during spring and most of summer, there was a massive drought. Due to the low rainfall in April and May $(30.6 \mathrm{~mm})$ the soil moisture values decreased at the end of May to less than $50 \%$ of the AWC. The first irrigation was therefore already urgently needed after seeding. The drought continued until August, so by this time, much watering had to be given with a total of $421 \mathrm{~mm}$ for $100 \%$ water balance (low soil quality) and $319 \mathrm{~mm}$ for $80 \%$ water balance (medium soil quality). Due to the 
subsequent high rainfall until harvest $(215 \mathrm{~mm})$ irrigation was discontinued.

Table 1: Irrigation application rates and crop yield of the trial years for sugar beet.

\begin{tabular}{|c|c|c|c|c|}
\hline $\begin{array}{l}\text { Irrigation } \\
\text { strategy }\end{array}$ & $\begin{array}{l}\text { Application } \\
\text { rate (mm) }\end{array}$ & $\begin{array}{l}\text { Sugar beet } \\
\text { production } \\
\quad(\mathbf{t} / \mathbf{h a})\end{array}$ & $\begin{array}{c}\begin{array}{c}\text { Sugar } \\
\text { production } \\
\text { (t/ha) }\end{array} \\
\text { (1) }\end{array}$ & $\begin{array}{c}\text { Sugar } \\
\text { percentage } \\
(\%)\end{array}$ \\
\hline \multicolumn{5}{|c|}{2013} \\
\hline $100 \%$ (Sandy) & 206 & 80.9 & 14.1 & 17.4 \\
\hline 80\% (Loamy) & 170 & 97.6 & 16.8 & 17.2 \\
\hline $\begin{array}{l}\text { Control (100\% } \\
\text { loamy) }\end{array}$ & 206 & 96.8 & 16.6 & 17.2 \\
\hline $\begin{array}{l}\text { Without } \\
\text { irrigation }\end{array}$ & - & 82.4 & 14.5 & 17.5 \\
\hline \multicolumn{5}{|c|}{2014} \\
\hline $100 \%$ (Sandy) & 421 & 78 & 13.8 & 17.7 \\
\hline 80\% (Loamy) & 319 & 97.8 & 16.7 & 17.1 \\
\hline $\begin{array}{l}\text { Control (100\% } \\
\text { loamy) }\end{array}$ & 421 & 97.1 & 16.8 & 17.3 \\
\hline $\begin{array}{l}\text { Without } \\
\text { irrigation }\end{array}$ & - & 57 & 10.2 & 17.9 \\
\hline
\end{tabular}

For the medium soil quality (loamy soil), the initial differences in the irrigation of 36 and $102 \mathrm{~mm}$ did not impact the yield compared with the control for 2013 and 2014 respectively. Compared to the area without irrigation was on the medium soil quality, a difference in yield of about 15.2 and 40.8 t/ha was available for 2013 and 2014 respectively.

In general, that means that the irrigation itself has a good impact, but the VRI could not be fully achieved for 2013, because of the heavy rains. On the other hand, water saving achieved through the VRI was $17.5 \%$ for the irrigation amount (5 irrigations). In 2014 growing season, the high impact for VRI on water saving could be noted (24.2\%). 
The difference in yield between plots with low and medium soil quality can only be explained by the better subsequent delivery of nutrients to the plant.

The heavy rainfall in the first season meant that the statistical analysis for the irrigation water deficit by VRI, difference in yield under the same soil conditions and between the non-irrigated plots for the two seasons could not be carried out.

The obtained knowledge was confirmed by the research into precision irrigation conducted in the world. Hedley et al. (2009) identified preciously the performance indicators of variable rate irrigation. That enabled us to determine accurately the amount of the consumed water, water losses, and nitrogen depletion from the soil depending upon concrete conditions of the selected fields. Water saving was from $9 \%$ up to $19 \%$ with an adequate reduction of energy consumption. It follows that water saving in our experiments was higher.

\section{CONCLUSION}

A VRI prescription was developed for the center pivot based on the site soil characteristics which provide a detailed irrigation schedule for each zone, tailored to the specific irrigation trigger point due to soil differences and aiming to maintain a small soil moisture deficit. This allows best use of stored water in the zones with larger water storage capacity and provides more frequent watering to zones with small water holding capacity. The field irrigation management zones and sugar beet production were determined through two years.

The results of the application tests indicated that the pivot's application was uniform in non-VRI mode. Similarly, when all sprinklers were set to $70 \%$, the application was again uniform, showing that the VRI system's cycling of sprinklers on/off to vary application rate did not alter the uniformity. The third series of tests mimicked a variable-rate scenario and the VRI system was able to achieve target application amounts fairly 
well. However, these tests measured variations in application only along the pivot mainline.

Due to the dry weather in the most of 2014 season, the differences were clearer than the high rainy year 2013. The results from the actual water use study indicated substantial water savings in the second season (24.2\%), while low change in water use existed in the first season $(17.5 \%)$. This is common with humid and sub-humid weather. Each season is a unique situation that has its own variability to be addressed. Sugar beet and sugar production were similar under full irrigation (100\% of water balance) and VRI (80\% of water balance) for loamy soil (medium quality) for both two seasons. The soil differences (low and medium quality) are likely, thereby having a greater impact.

In general, the gain in two years is very high. Furthermore, results are to be taken into consideration from two different years of the trial, which can have a preliminary use for sugar beet, especially in sub-humid areas. It would be highly recommended to perform a continuation of the irrigation experiments in tropical areas which depend completely on irrigation. It will be helpful to obtain actual water savings and crop yields realized from use of VRI controls.

\section{ACKNOWLEDGEMENT}

The authors thank the EU for financial support and the staff of the Chamber of Agriculture of Lower Saxony and the Braunschweig DWD for the good cooperation. Special thanks go to the farmer (Mr. Hartmut Becker) for the land made available and the center pivot. The first author would like to present deep gratefulness and appreciation to Benha University, Egypt (www.bu.edu.eg) and Thünen Institute for Agricultural Technology (TI), Braunschweig, Germany, for giving him the opportunity to fulfill this study.

\section{REFERENCES}

Al-Kufaishi, S., S. Blackmore, H. Sourell, and G. Maletti (2005). Assessment of two variable rate irrigation controllers used on a 
centre pivot. Agr. Eng. Int.: the CIGR Ejournal. Manuscript LW 05 002. Vol. VII.

ASABE (2012). S436.1: Test procedure for determining the uniformity of water distribution of center pivot and lateral move irrigation machines equipped with spray or sprinkler nozzles. St. Joseph, MI: ASABE.

Evans, R. G., J. LaRue, K. C. Stone, and B.A. King (2013). Adoption of site-specific variable rate sprinkler irrigation systems. Pub. from USDA-ARS / UNL Fac. Paper 1245. http://digitalcommons.unl.edu/usdaarsfacpub/1245 (accessed on March 2014).

Evans, R. G., J. LaRue, K. C. Stone, and B. A. King (2012). Adoption of site-specific variable rate sprinkler irrigation systems. Irrigation Science:1-17.

Farmscan (2011). Operator's manual. http://advancedagsystems.com/PDF/7000VRI_USA.pdf

Fraser, T. (2011). Variable-rate irrigation. landcare research. http://www.ourfuture.net.nz/Stories/122 (accessed on August 2013).

Hedley C., I. Yule, M. Tuohy, and I. Vogeler (2009). Key performance indicators for variable rate irrigation implementation on variable soils. St. Joseph, ASABE.

Hedley, C. B. and I. J. Yule (2009). Soil water status mapping and two va riable-rate irrigation scenarios. Precision Agriculture 10(4):342 -355 .

Hezarjaribi, A., H. Sourell, and F-J. Bockisch (2008). Site-specific for subfields: Development of irrigation map and a dynamic control for center pivot. Landtechnik, volume 63(3), Pp: 154-155, in German.

Kikiras, P.C., and D. Drakoulis (2003). The European approach to augmented satellite based positioning systems and their application 
in precision farming, proceedings of the Int. Symp. at Volos, Greece, 7-9, Nov. 2003.

Konstantinos, K., X.Apostolos, K. Panagiotis, and S. George (2007). Topology optimization in wireless sensor networks for precision agriculture applications. Sensor Tec. and Apps. 2007. Int. Conf. on sensor Comm.: 526-530.

Liu X. and X. Li, (2013). Application of information technology for Precision agriculture. ASABE Ann. Int. Mtg. Spon. by ASABE Kansas City, Missouri July $21-24$.

McCarthy, A.C., N.H. Hancock, and S.R. Raine (2010). VARIwise: A general-purpose adaptive control framework for spatially and temporally varied irrigation at sub-field level. Computers and Electronics in Agr., 70: 117-128.

Thörmann, H-H, K. Nolting, M. Kraft, and H. Sourell (2012). Possibilities of precision irrigation. Aquarius - Proj. report. Agr. chamber Lower Saxony District at Uelzen.: 101-119, in German.

Vellidis, G. 2005. A real-time smart sensor array for scheduling irrigation in cotton, NESPAL - Nat. Envi. Sound Prod. Agr. Lab.

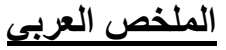
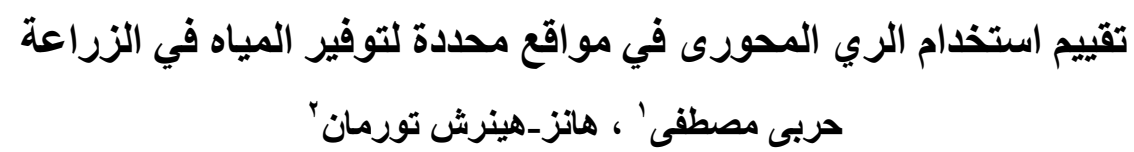

نظم الرى المحورى يمكن أن تعطى معدلات إضافه مختلفة من المياه عن طريق التحكم فى

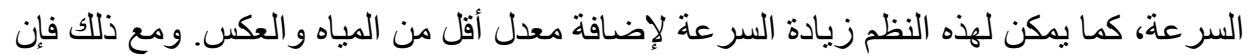

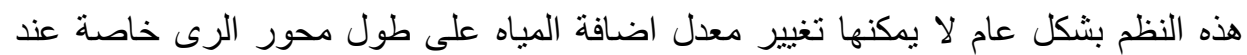

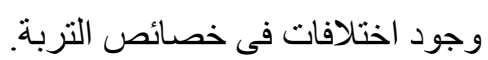
إن الاختلاف فى خصائص وبناء التربة تحت نظام الرى المحورى الو احد يؤدى إلى زيادة الرىى عن المطلوب فى المناطق الرطبه أو نقص معدل الاضافة فى المناطق ذات الرئ النفاذية العالية

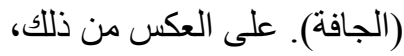


فإن استخدام طريقة رى المو اقع المحدده مع نظام الرى المحورى يمكنها من اضافة معدل الماء

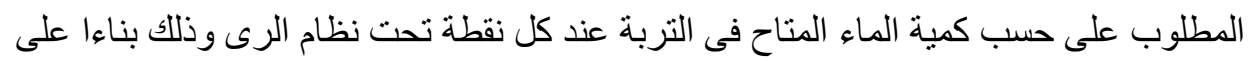
خريطة توزيع رطوبة التربة.

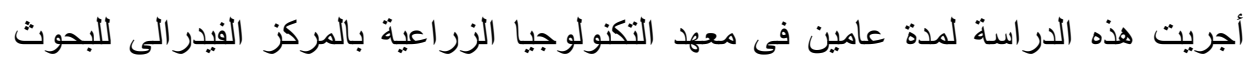

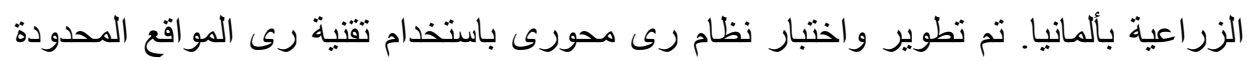

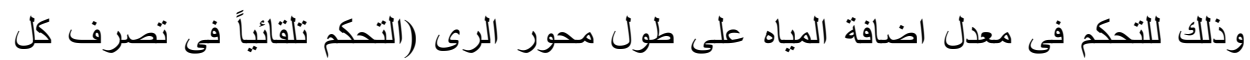

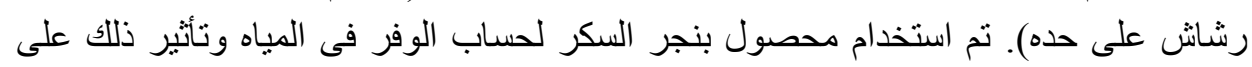
الانتاجية.

أظهرت النتائج توفير واضح فى معدل الرى بمقدار ب ـ ا مم خلال الموسم الثانى (قلة الامطار الساقطة) فى حين كان بr مم فى الموسم الأول وذللك بسبب المعدل العالى لسقوط الأمطار.

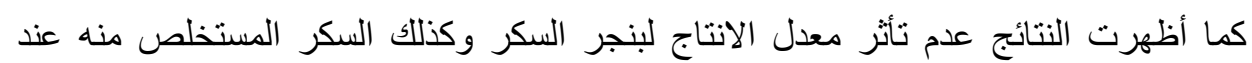

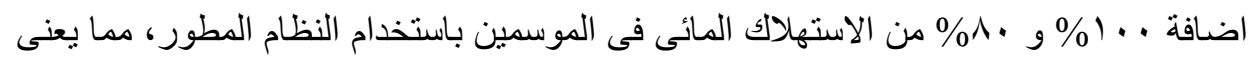

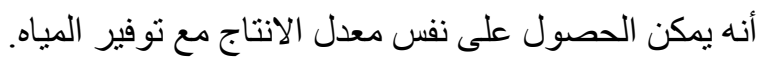

